\title{
Matrilin-3 Induction of IL-1 receptor antagonist Is required for up-regulating collagen II and aggrecan and down-regulating ADAMTS-5 gene expression
}

\author{
Chathuraka T Jayasuriya', Mary B Goldring ${ }^{2}$, Richard Terek ${ }^{1}$ and Qian Chen ${ }^{1 *}$
}

\begin{abstract}
Introduction: Deletion or mutation of the gene encoding the cartilage extracellular matrix (ECM) protein matrilin-3 (MATN3) results in the early onset of osteoarthritis (OA), suggesting chondroprotective properties of MATN3. To understand the mechanisms underlying these properties, we determined the effects of MATN3 protein on the expression of several key anabolic and catabolic genes involved in chondrocyte homeostasis, and the dependence of such regulation on the anti-inflammatory cytokine: IL-1 receptor antagonist (IL-1Ra).

Methods: The effects of recombinant human (rh) MATN3 protein were examined in C28/12 immortalized human chondrocytes, primary human chondrocytes (PHCs), and primary mouse chondrocytes (PMCs). Messenger RNA levels of IL-1Ra, COL2A1, ACAN, MMP-13, and ADAMTS-4 and -5 were determined using real-time RT-PCR. Knocking down IL-1Ra was achieved by siRNA gene silencing. IL-1Ra protein levels were quantified by ELISA and the Bio-Plex Suspension Array System. COL2A1 protein level was quantified using Western blot analysis. Statistic analysis was done using the two-tailed t-test or one-way ANOVA.
\end{abstract}

Results: rhMATN3 protein induced gene expression of IL-1Ra in C28/I2 cells, PHCs, and PMCs in a dose- and timedependent manner. Treatment of C28/I2 cells and PHCs with MATN3 protein stimulated gene expression of COL2A1 and ACAN. Conversely, mRNA levels of COL2A1 and ACAN were decreased in MATN3 KO mice. MATN3 protein treatment inhibited IL-1 $\beta$-induced MMP-13, ADAMTS-4 and ADAMTS-5 in C28/I2 cells and PHCs. Knocking down IL-1Ra abolished the MATN3-mediated stimulation of COL2A1 and ACAN and inhibition of ADAMTS-5, but had no effect on MATN3 inhibition of MMP-13 mRNA.

Conclusion: Our findings point to a novel regulatory role of MATN3 in cartilage homeostasis due to its capacity to induce $I L-1 R a$, to upregulate gene expression of the major cartilage matrix components, and to downregulate the expression of OA-associated matrix-degrading proteinases in chondrocytes. The chondroprotective properties of endogenous MATN3 depend partly on its induction of IL-1Ra. Our findings raise a possibility to use rhMATN3 protein for anti-inflammatory and chondroprotective therapy.

Keywords: Matrilin-3, interleukin-1, IL-1Ra, collagen 2, aggrecan, MMP-13, ADAMTS-4, ADAMTS-5, chondrocytes, osteoarthritis

\footnotetext{
* Correspondence: Qian_Chen@brown.edu

'Department of Orthopedics; Warren Alpert Medical School of Brown

University, Providence RI 02903, USA

Full list of author information is available at the end of the article
} 


\section{Introduction}

Matrilin-3 (MATN3) is one of the four members of the matrilin family of noncollagenous oligomeric ECM proteins [1-4]. As the smallest member of this family, it contains a single Von Willebrand Factor A (vWFA) domain, four epidermal growth factor (EGF)-like domains, and an alpha-helical oligomerization domain, which allows it to form oligomers with itself or other matrilin molecules [5]. As an extracellular matrix (ECM) protein, MATN3 was thought to play a major structural role in forming a filamentous matrix network by interacting with collagen fibrils, multiple proteoglycans, and other glycoproteins [5]. Mutations in human MATN3 are associated with a variety of skeletal diseases including multiple epiphyseal dysplasia (MED), spondylo-epi-metaphyseal dysplasia (SEMD), and osteoarthritis (OA) [6-9], underscoring its importance in cartilage development and homeostasis. Deletion of the MATN3 gene in mice results in no gross skeletal deformity at birth; it does however, cause acceleration of cartilage degeneration during aging [10]. Furthermore, MATN3 gene expression is increased in articular cartilage tissues from OA patients [11].

$\mathrm{OA}$ is characterized as a disregulation of cartilage homeostasis due to excessive upregulation of catabolic factors and the inability of the chondrocytes to adequately repair the degraded matrix, resulting ultimately in degeneration of the major cartilage ECM components such as type II collagen fibrils and aggrecan [12-15]. ECM catabolism is largely mediated by the matrix metalloproteinase (MMP) family of collagenases, including MMP-13, and by the ADAMTS family of aggrecanases (ADAMTS-4 and -5) [14-21]. They are often expressed in chondrocytes in response to major inflammatory cytokines such as IL-1 $\beta$ produced by the synovium and other joint tissues [12]. Furthermore, there is a correlation between the increased levels of these catabolic enzymes and inflammatory mediators such as prostaglandins, nitric oxide (NO), and pro-inflammatory cytokines such as IL-1 $\beta$ and TNF- $\alpha$ in synovial fluids and joint tissue. Previous studies have implicated IL- $1 \beta$ as one of the major inflammatory cytokines associated with cartilage damage [12,22-25] due to its ability to induce or upregulate the expression of proteinases, including MMPs, plasminogen activator, and aggrecanases [25-30], and to downregulate the expression of endogenous proteinase inhibitors (for example, certain TIMPs) [22,31] and cartilage matrix components such as COL2A1 and ACAN [32-34]. IL-1 stimulates production of pro-inflammatory factors including prostaglandins, leukotrienes and itself $[12,35,36]$. Importantly, IL-1, IL-1 receptor, and MMPs are expressed by chondrocytes in OA cartilage and can be immunolocalized to the same regions [37-40]. Inhibition of the IL-1 $\beta$ pathway presents a promising means of preventing cartilage degradation during OA pathogenesis.
One of the major endogenous inhibitors of the IL-1 pathway is IL-1 receptor antagonist (IL-1Ra) [41-43].

In this study we aimed to test whether MATN3 can positively regulate cartilage homeostasis genes, including those downstream of IL-1, in a manner that can help explain its chondroprotective function. Here we report for the first time several novel regulatory functions of MATN3 including induction of $I L-1 R a$, stimulation of COL2A1 and ACAN expression, and inhibition of MMP13 and $A D A M T S-4$ and -5 expression. We also tested whether these novel regulatory properties of MATN3 depend on its induction of $I L-1 R a$.

\section{Methods}

\section{MATN3 knockout animals}

For the purpose of comparing Col2a1 and Acan expression between wild-type and MATN3 knockout (KO) mice of the same C57BL/6J genetic background, mRNA was extracted from the whole hind limbs of these mice at embryonic day 18.5. Generation of MATN3 KO mice have previously been described [10]. An in-frame stop codon was introduced into the second exon of their MATN3 gene via homologous recombination during the embryonic stem cell stage, rendering these mice functionally MATN3-null animals. All experiments were performed with the approval of the Rhode Island Hospital Institutional Animal Care and Use Committee (IACUC, number 0231-11).

\section{Isolation of primary chondrocytes from human and mouse cartilage}

Primary mouse chondrocytes (PMCs) were isolated from the rib cages of 6-day-old mice. Primary human chondrocytes (PHCs) were isolated from normal-looking areas of knee articular cartilage obtained from five patients undergoing total joint replacement surgery. Cartilage samples were individually handled and processed separately to isolate chondrocytes. Each cartilage sample was washed twice with sterile PBS within 2 hours of tissue collection and diced into small fragments. Cartilage fragments were digested in $5.0 \mathrm{ml}$ of Pronase (Roche, Indianapolis, IN, USA) in Hank's Balanced Salt Solution (HBSS) at a concentration of $2.0 \mathrm{mg} / \mathrm{ml}$ for 30 minutes at $37^{\circ} \mathrm{C}$ under shaking conditions. The digestion solution was removed and cartilage was washed twice with DMEM medium (Life Technologies, Grand Island, NY, USA). After a second wash, DMEM was removed and replaced with $5.0 \mathrm{ml}$ of Type IA Crude Bacterial Collagenase (Sigma-Aldrich, St. Louis, MO, USA) at $1.0 \mathrm{mg} / \mathrm{ml}$ for 8 hours at $37^{\circ} \mathrm{C}$ under shaking conditions. Collagenase enzyme reaction was stopped by adding $5.0 \mathrm{ml}$ of DMEM medium containing 10\% fetal bovine serum (FBS) (Life Technologies) into the digestion mix. Solution was filtered using a $100 \mu \mathrm{m}$ nylon cell strainer (BD, Franklin Lakes, NJ, USA) to 
remove clumps, followed by centrifugation at $1500 \mathrm{rpm}$ to pellet the successfully isolated chondrocytes. Pellet was washed twice with DMEM medium and cells were counted using a hemocytometer. Finally, chondrocytes were plated at high density $\left(4.0 \times 10^{6}\right.$ cells $)$ in 60 -mm cell culture dishes using DMEM medium supplemented with $10 \%$ FBS and $0.2 \%$ Streptomycin (Life Technologies). All studies involving patient tissue samples were conducted in accordance with the Institutional Review Board (IRB) of Rhode Island Hospital. The need to obtain patient consent for the collection of cartilage tissue after surgery was waived by the Rhode Island Hospital IRB.

\section{Chondrocyte cell culture studies}

Cell culture experiments were conducted using PMCs, PHCs, and C28/I2 immortalized human chondrocytes, and involved first plating cells in 6-well culture plates at 200,000 viable cells per well in 1:1 DMEM/F-12 media (Life Technologies) supplemented with 10\% FBS. After 48 hours, the culture medium was replaced with $2.0 \mathrm{ml}$ of serum-free 1:1 DMEM/F-12 and incubated for 5 hours prior to treatment with recombinant human (rh) MATN3 protein $(100 \mathrm{ng} / \mathrm{ml}$ or $200 \mathrm{ng} / \mathrm{ml})$ (R\&D Systems, Minneapolis, MN, USA) and/or rhIL-1 $\beta$ (5.0 ng/ml) (PeproTech, Rocky Hill, NJ, USA) for 8 to 36 hours, unless otherwise stated. To optimize the induction of catabolic proteases (that is, MMP-13, ADAMTS family) by IL-1 in both primary and immortalized chondrocytes, we used serum-free media for the duration of the treatment period as in a previous study [44].

\section{Small interfering RNA-based silencing of IL-1Ra in PHCs}

PHCs were transfected for 48 hours at approximately 40 to $50 \%$ cell confluency with a small interfering RNA (IL1RN ON-TARGETplus siRNA) (Dharmacon, Chicago, IL, USA) using Lipofectamine 2000 (Invitrogen, Carlsbad, CA, USA) according to the manufacturer's instructions. The siRNA targets and suppresses the mRNA and protein expression of all four endogenous isoforms of human IL-1Ra. A non-silencing siRNA (Allstars Negative Control siRNA) (Qiagen, Valencia, CA, USA) was used as control. PHCs were plated at 200,000 viable cells per well in 6-well culture plates 24 hours prior to siRNA transfection procedure. For each well, 40 pmol of siRNA and $2.0 \mathrm{uL}$ of Lipofectamine 2000 were utilized for transfection. The 40 pmol of siRNA was first diluted in $100 \mathrm{uL}$ of OptiMEM I Reduced Serum Media. Likewise, $2.0 \mathrm{uL}$ of Lipofectamine 2000 was diluted in $100 \mathrm{uL}$ of Opti-MEM I Reduced Serum Media. After 5 minutes at room temperature, the siRNA and lipid mediator solutions were gently mixed, incubated at room temperature for 20 minutes, and then added to cell culture wells containing $1.0 \mathrm{ml}$ of incomplete DMEM media. Cells were placed in a $37^{\circ} \mathrm{C}$ incubator and media was changed after 8 hours. PHCs were treated with MATN3 and/or IL-1 $\beta 48$ hours post transfection for subsequent cell culture experiments.

\section{Gene expression analysis}

Total RNA was isolated from PMCs, PHCs, C28/I2 cells and the hind limbs of embryonic day 18.5 wild-type and MATN3 $\mathrm{KO}$ mice on the C57BL/6J genetic background [10] using the RNAqueous Kit (Ambion, Austin, TX, USA) according to the manufacturer's instructions. Gene expression analysis was conducted by real time quantitative PCR (RT-qPCR) with the DNA Engine Opticon 2 (Bio-Rad, Hercules, CA, USA) using the QuantiTect SYBR Green PCR kit (Qiagen). For RT-qPCR, 0.5 ug of RNA was reverse-transcribed using iScript cDNA Synthesis Kit (Bio-Rad) according to the manufacturer's instructions. The cDNA of each sample was subjected to RT-qPCR using species-specific primer pairs for genes encoding $I L$ 1Ra, type II collagen, aggrecan, MMP-13, and soluble (s)IL$1 R a$. Exact primer sequences can be found in Table 1. Relative transcript levels were calculated using the deltadelta $\mathrm{Ct}(\Delta \Delta \mathrm{Ct})$ method, normalized to rRNA $18 \mathrm{~S}$ expression according to the following equation: $\mathrm{X}=2^{-\Delta \Delta \mathrm{Ct}}$, in which $\Delta \Delta C t=\left(\mathrm{Ct}_{\mathrm{Exp}}-\mathrm{Ct}_{18 \mathrm{~S}}\right)-\left(\mathrm{Ct}_{\mathrm{Ctl}}-\mathrm{Ct}_{18 \mathrm{~S}}\right)$ and $\mathrm{X}=$ Relative transcript; $\mathrm{Ct}_{\mathrm{Ctl}}=\mathrm{Ct}$ of control group.

\section{Protein analysis}

The Human IL-1ra/IL-1F3 Immunoassay (R\&D Systems) and the MMP-13 Human ELISA Kit (Abcam, Cambridge, MA) were used to quantify IL-1Ra and MMP-13 protein levels, respectively, in PHCs 24 hours following treatment with MATN3 and/or IL-1 $\beta$, according to the manufacturer's instructions. PHCs were seeded at a cell density of 100,000 cells/well in 12-well cell culture plates. After 24 hours, media were changed to be serum-free and each group was treated with MATN3 and/or IL-1 $\beta$ as appropriate. Conditioned media were collected 24 hours later, spun down to remove any cell debris and immediately frozen down at $-80^{\circ} \mathrm{C}$ until assays were ready to be performed. The minimum detectable level of IL-1Ra and MMP-13 by these assays were $30 \mathrm{pg} / \mathrm{ml}$ and $6.0 \mathrm{pg} / \mathrm{ml}$, respectively.

The Bio-Plex Suspension Array System (Bio-Rad) was used to measure soluble IL-1Ra protein levels in cell culture medium of PHCs transiently transfected with either an siRNA against $I L-1 R a$ or a non-silencing scrambled control siRNA. Transiently transfected PHCs were collected 36 hours following treatment with MATN3 and/or IL-1 $\beta$. These samples were analyzed using Bio-Plex Pro Human Cytokine Assay in duplicate per each biological replicate (two per treatment group) according to the manufacturer's instructions. Protein quantification of type II collagen was conducted via western blot analysis 
Table 1 Forward and reverse primer sequences used for real-time PCR

\begin{tabular}{llll}
\hline Species & Gene & Forward sequence & Reverse sequence \\
Human & ADAMTS-4 & 5'-CCCCAGACCCCGAAGAGCCA-3' & 5'-CCCGCTGCCAGGCACAGAAG-3' \\
Human & ADAMTS-5 & 5'-GGCCGTGGTGAGGTGGTGG-3' & 5'-GCTGCGTGGAGGCCATCGTC-3' \\
Human & ACAN & 5'-ACCAGACGGGCCTCCCAGAC-3' & 5'-TGGCTCTGCCCCAGAGGGAC-3' \\
Human & COL21A & 5'-TGAGGGCGCGGTAGAGACCC-3' & 5'-TGCACACAGCTGCCAGCCTC-3' \\
Human & IL-1Ra (pair 1)* & 5'-CCCGTGAAGGAGAGCCCTTCATTTG-3' & 5'-ACTITCACCATCATTCACAAATGCAG-3' \\
Human & IL-1Ra (pair 2)** & 5'-TGTTCCATTCAGAGACGATCTGCCG-3' & 5'-GAGCATGAGGCTCAATGGGTACC-3' \\
Human & MMP-13 & 5'-ATGCGGGGTTCCTGATGTGG-3' & 5'-GGCCCAGGAGGAAAAGCATG-3' \\
Murine & Acan & 5'-CAGTGCGATGCAGGCTGGCT-3' & 5'-CCTCCGGCACTCGTTGGCTG-3' \\
Murine & Col2al & 5'-CACACTGGTAAGTGGGGCAAGACCG-3' & 5'-GGATTGTGTGTTCAGGGTTCGGG-3' \\
Murine & IL-1Ra & 5'-ACCCATGGCTTCAGAGGCAGC-3' & 5'-GCCCCCGTGGATGCCCAAG-3'
\end{tabular}

*Primer pair used for IL-1Ra expression analysis in C28/I2 immortalized human chondrocytes and primary human chondrocytes for Figure 1A, 1C and Additional file 1. **Primer pair used for IL-1Ra expression analysis in primary human chondrocytes for Figure 4A and 4B. ACAN, aggrecan; COL2A1, type II collagen; IL-1Ra, interleukin-1 receptor antagonist; MMP-13, matrix metalloproteinase-13.

using standard protocols. Prior to Western blot analysis of type II collagen protein, primary human chondrocytes transfected with either the $I L-1 R a$-silencing siRNA or the non-silencing scrambled control siRNA, were seeded and cultured for 48 hours in DMEM containing 10\% FBS in the presence and absence of rhMATN3 (200 ng/ml) and/ or IL-1 $\beta(5.0 \mathrm{ng} / \mathrm{ml})$. Cell culture pellets were resuspended in $50 \mathrm{uL}$ of RIPA buffer (Cell Signaling Technology, Boston, MA, USA) containing protease inhibitors. Protein concentrations were determined using a Bradford Assay (Bio-Rad), according to the manufacturer's instructions, and a NanoDrop 2000c (Thermo Fisher Scientific, Rockford, IL, USA). Western blot analysis was performed using standard protocols. A previously characterized mAb against collagen II $[45,46]$ (NeoMarkers, Fremont, CA, USA) was used as the primary antibody. Beta-actin was used as a loading control for normalization. Imaging was done using the Odyssey Infrared Imager (LI-COR Biosciences, Lincoln, NE, USA). Western band intensities were quantified using Image software program $(\mathrm{NIH}$, Bethesda, MD, USA).

\section{Statistical analysis}

Mean values were calculated and are presented with error bars representing \pm SDM (one standard deviation of the mean). Two-tailed $t$-tests were used to analyze data represented in Figure 1B and 2D. For all else, statistical analysis was done using one-way analysis of variance (ANOVA) followed by post hoc test analysis. Statistical significance was accepted at $P<0.05$ for all analyses.

\section{Results}

MATN3 induces gene expression of IL-1Ra

IL-1Ra is a potent endogenous inhibitor of the IL-1 pathway $[37,38]$. To determine whether MATN3 affects IL-1Ra synthesis, we treated immortalized human C28/ I2 chondrocytes with rhMATN3 protein. MATN3 induced mRNA expression of $I L-1 R a$ in a dose- dependent manner (Figure 1A). We also observed an increase of $I L-1 R a$ mRNA levels in PMCs treated with rhMATN3 protein (Figure $1 \mathrm{~B}$ ). RhMATN3 protein induced $I L-1 R a$ mRNA in PHCs in the presence or absence of IL-1 $\beta$ (Figure $1 C$ ). Treating PHCs with MATN3 in the presence of IL- $1 \beta$ significantly enhanced IL-1Ra protein concentration in culture medium compared to that of cells treated with IL-1 $\beta$ alone (Figure 1D). The kinetics of $I L-1 R a$ mRNA induction by MATN3 in C28/I2 cells and PHCs was also analyzed (see Additional file 1). The induction of $I L-1 R a$ mRNA persisted during a 24-hour treatment period with more pronounced induction in the shorter incubation period. Thus, MATN3 induces the mRNA and protein expression of IL-1Ra in chondrocytes.

\section{MATN3 stimulates expression of COL2A1 and ACAN}

To investigate whether MATN3 stimulates type II collagen gene (COL2A1) expression in chondrocytes, we treated C28/I2 cells (Figure 2A) and PHCs (Figure 2B) with rhMATN3 protein for 8 hours. We observed a significant induction of COL2A1 expression in these chondrocytes. MATN3 induction of COL2A1 was also observed after 24 hours treatment (see Additional file 2). While treatment with IL-1 $\beta$ significantly decreased COL2A1 mRNA levels in both C28/I2 cells and PHCs, treatment with MATN3 at the same time reversed this decrease (Figure 2A,B). MATN3 treatment also increased aggrecan gene $(A C A N)$ expression by $\mathrm{PHCs}$ in the presence of IL-1 $\beta$ (Figure $2 \mathrm{C}$ ).

To determine whether the lack of $M A T N 3$ affects the expression of COL2A1 and $A C A N$ in chondrocytes, we analyzed RNA isolated from the limbs of MATN3 KO and wild-type mice. The MATN3 KO mice exhibited 50\% reduction of Col2a1 and Acan mRNA levels compared to their wild-type littermates (Figure 2D) indicating that the absence of MATN3 suppresses the expression of these two genes. 
A

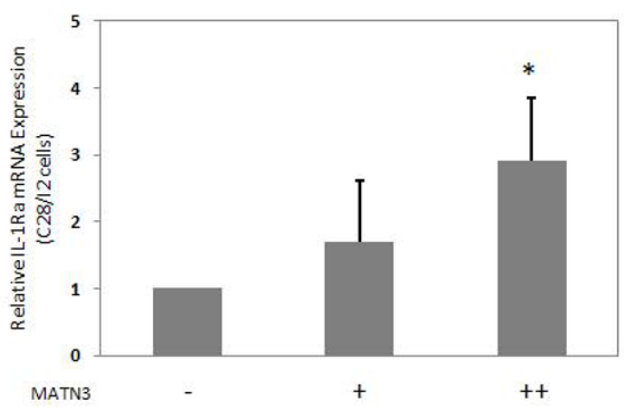

C

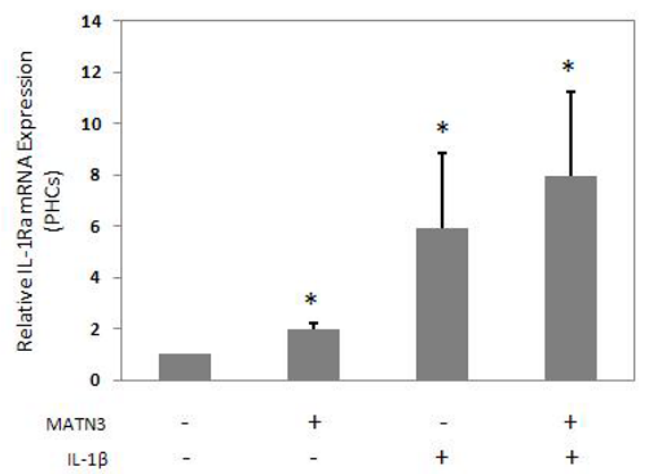

B

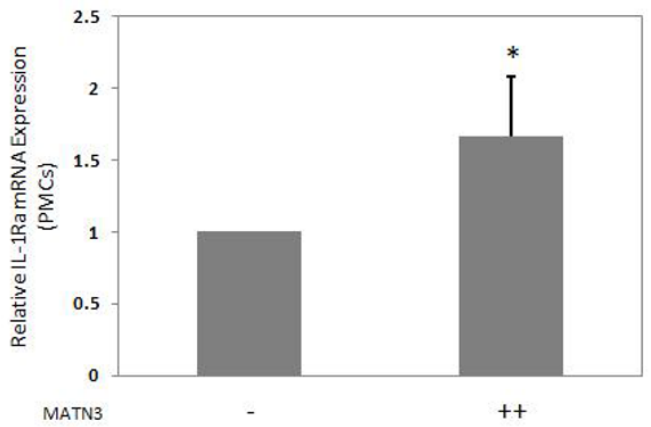

D

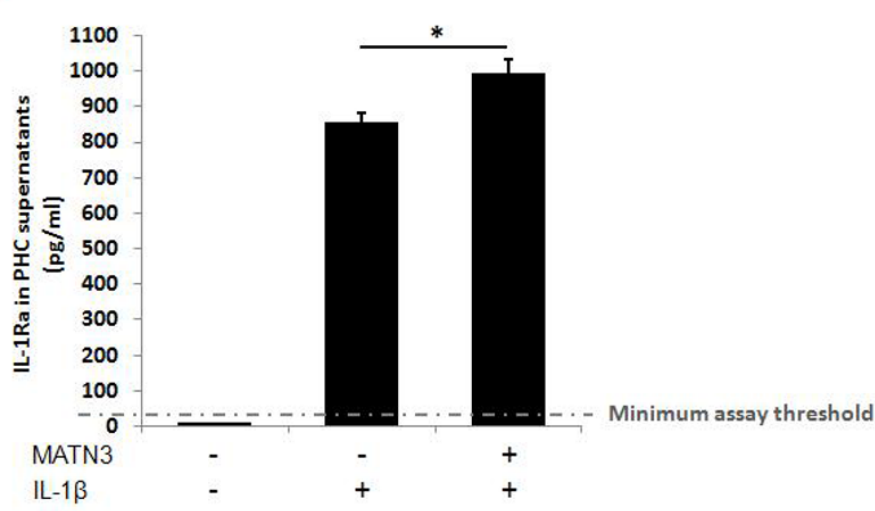

Figure 1 Matrilin-3 MATN3) enhances IL-1Ra expression by chondrocytes. Recombinant human (rh) MATN3 protein enhances the gene expression of IL-1Ra in a dose-dependent manner at 12 hours post cell culture treatment as seen here in C28/I2 cells (A). Recombinant MATN3 also enhances IL-1Ra expression in primary mouse chondrocytes after 24 hours of treatment (B). MATN3-induced IL-1Ra gene expression is evident in primary human chondrocytes (PHCs) at 24 hours post treatment in both the presence and absence of IL-1 $\beta$ (C). PHCs treated with both MATN3 and IL-1 $\beta$ for 24 hours exhibit significantly higher concentrations of IL-1Ra protein in their cell media, relative to the media of cells treated with IL-1 $\beta$ alone (D). In these experiments, rh MATN3 protein is used at one of two concentrations: lower dose (+) of 100 ng/ml, or higher dose $(++)$ of $200 \mathrm{ng} / \mathrm{ml}$. Rh IL-1 $\beta$ protein treatment is always $5.0 \mathrm{ng} / \mathrm{ml}$. *Significant differences $(P \leq 0.05)$ from the untreated control group; " significant differences $(P \leq 0.05)$ from the IL-1 $\beta$ only treated group. Data are representative of three individual experiments.

MATN3 inhibits gene expression of MMP-13, ADAMTS-4 and ADAMTS-5

We next examined whether MATN3 could inhibit the expression of IL-1 $\beta$-induced protease genes. In C28/I2 cells, IL-1 $\beta$ treatment increased $M M P-13$ mRNA levels and MATN3 treatment decreased $M M P-13$ expression in both the presence and absence of IL-1 $\beta$ (Figure 3A). IL$1 \beta$ treatment also increased $M M P-13$ gene expression by PHCs and elevated $M M P-13$ mRNA levels and protein concentrations in $\mathrm{PHC}$-conditioned media while treatment with MATN3 abrogated this increase significantly (Figure 3B, C). Likewise, the IL-1 $\beta$-induced ADAMTS-4 and -5 gene expression was inhibited by MATN3 in C28/ I2 cells (Figure 3D), and in PHCs (Figure 3E).

\section{IL-1Ra mRNA and soluble protein levels are diminished} by IL1Ra siRNA

Previous studies have shown that IL-1Ra antagonizes IL-1 $\beta$ stimulation of catabolic gene expression and its inhibition of anabolic gene expression. We hypothesize that the chondroprotective properties of MATN3 are dependent on its upregulation of $I L-1 R a$. To test whether MATN3 acts through IL-1Ra to regulate the expression of anabolic and OA-associated catabolic genes, we first knocked down all isoforms of IL-1Ra using a small interfering RNA (siRNA). Since the endogenous soluble IL-1Ra protein levels present in C28/I2 cell supernatants were too low to accurately quantify, all knock-down experiments were conducted in PHCs. The siRNA transfection successfully knocked down both $I L-1 R a$ mRNA (Figure 4A, B) and protein expression (Figure $4 \mathrm{C}$ ) in $\mathrm{PHCs}$, both in the presence and absence of IL-1 $\beta$.

\section{MATN3 stimulation of COL2A1 and ACAN depends on IL-1Ra}

We then determined the effect of MATN3 on COL2A1 expression in $I L-1 R a$ knocked-down PHCs. In the control 
A

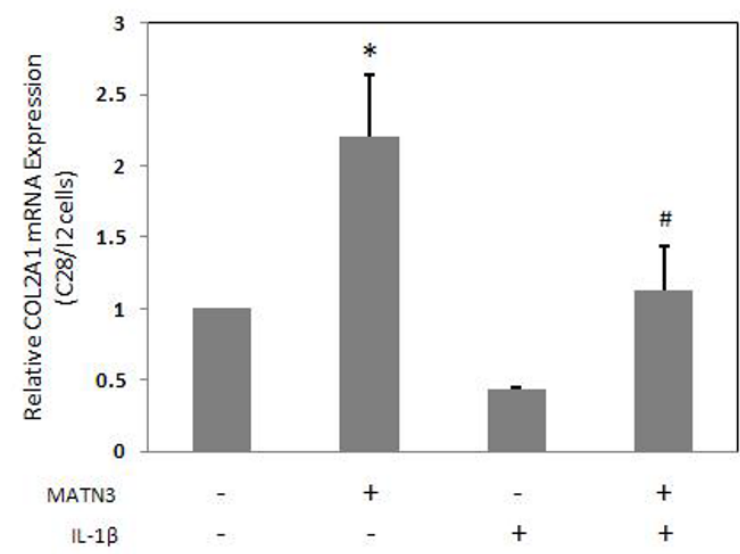

C

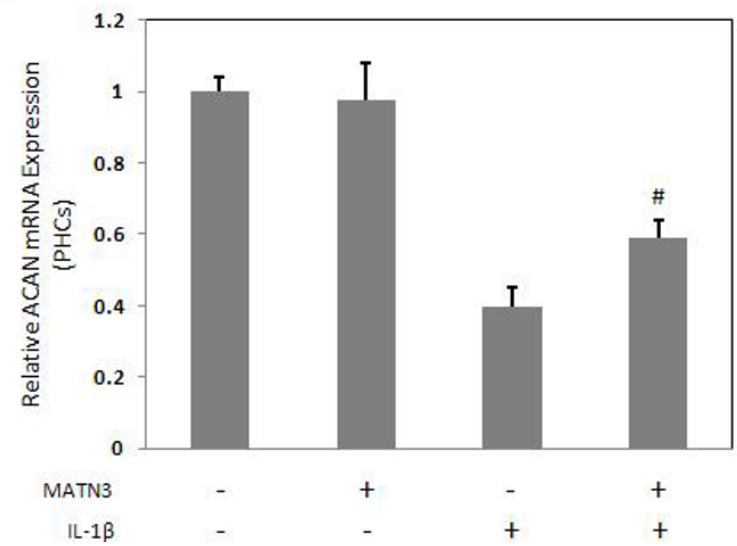

B

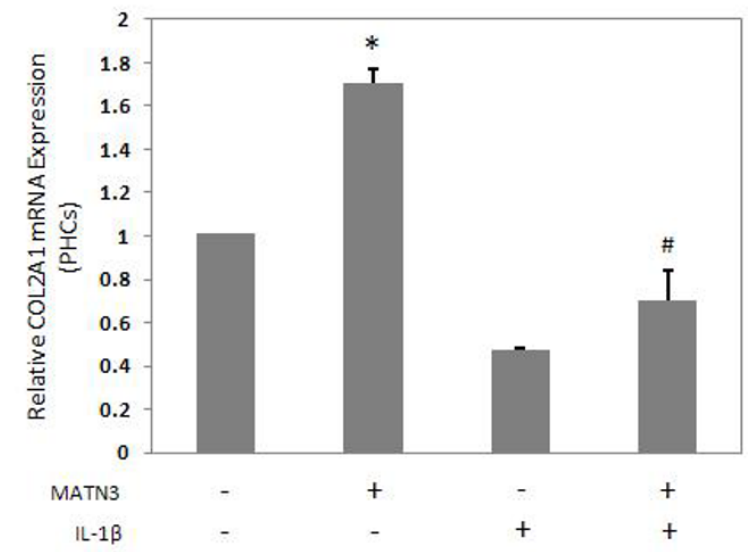

D

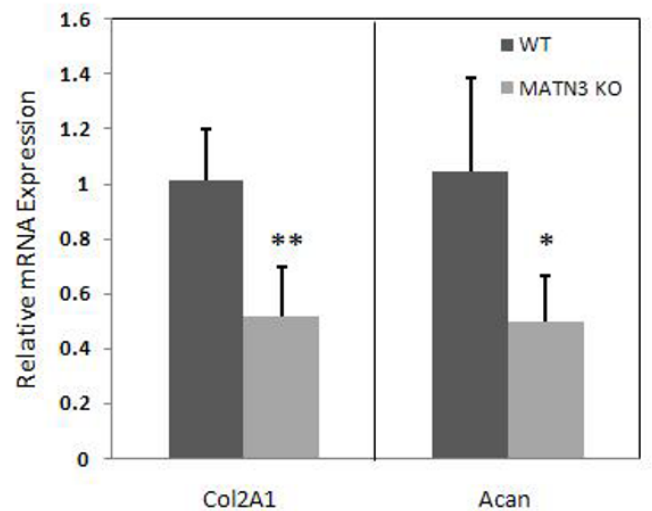

Figure 2 Matrilin-3 (MATN3) maintains the expression of key cartilage extracellular matrix (ECM) genes. Recombinant human (rh) MATN3 treatment maintains type II collagen (COL2A1) gene expression in the presence and absence of IL-1 $\beta$ in C28/I2 cells (A) and primary human chondrocytes (PHCs) (B) at 8 hours. MATN3 also inhibits the IL-1 $\beta$-induced downregulation of aggrecan (ACAN) gene expression in PHCs at 36 hours (C). Whole limb mRNA analysis of newborn MATN3 knockout (KO) mice of the C57BL/6J background reveal lower basal gene expression of Col21a and Acan compared to wild-type mice of the same genetic background (D). For all cell culture experiments, rh MATN3 protein is used at $200 \mathrm{ng} / \mathrm{ml}$. Rh IL-1 $\beta$ protein treatment is always $5.0 \mathrm{ng} / \mathrm{ml}$. * Significant differences $(P \leq 0.05)$ from the untreated control group; ${ }^{\#}$ significant differences $(P \leq 0.05)$ from the IL-1 $\beta$ only treated group. For cell culture experiments, data are representative of three individual experiments $(n=$ 5 for mouse whole limb mRNA studies).

cells, which were transfected with a scrambled siRNA construct, MATN3 treatment rescued the IL-1 $\beta$ induced downregulation of COL2A1 mRNA (Figure 5A, left). COL2A1 protein levels were also enhanced by MATN3 treatment in both the absence and presence of IL-1 $\beta$ (Figure 5B). In contrast, MATN3 was incapable of enhancing COL2A1 mRNA (Figure 5A, right) or protein levels (Figure $5 \mathrm{~B}$ ) in cells transfected with the IL-1Ra siRNA. Similarly, MATN3 reduced the extent of IL- $1 \beta$-induced downregulation of $A C A N$ mRNA expression in cells transfected with the scrambled siRNA construct (Figure $5 \mathrm{C}$, left) but not in cells transfected with the IL-1Ra siRNA (Figure 5C, right).

\section{MATN3 inhibition of ADAMTS-5, but not of MMP-13, depends on IL-1Ra}

To test whether MATN3 inhibition of matrix proteases is dependent on IL-1Ra, we quantified their expression levels in the $I L-1 R a$ knock-down chondrocytes. Knocking down $I L-1 R a$ chondrocytes significantly increased the basal level of ADAMTS-5 expression (Figure 6A, compare conditions in the absence of MATN3 or IL-1 $\beta$ ). The presence of MATN3 significantly inhibited the upregulation of ADAMTS- 5 by IL- $1 \beta$ (Figure 6A, left panel, $P \leq 0.05$ ). However, this inhibition was not significant in $I L-1 R a$ knock-down chondrocytes (Figure 6A, right panel, $P=$ 0.37). Thus MATN3 inhibition of ADAMTS-5 is at least 


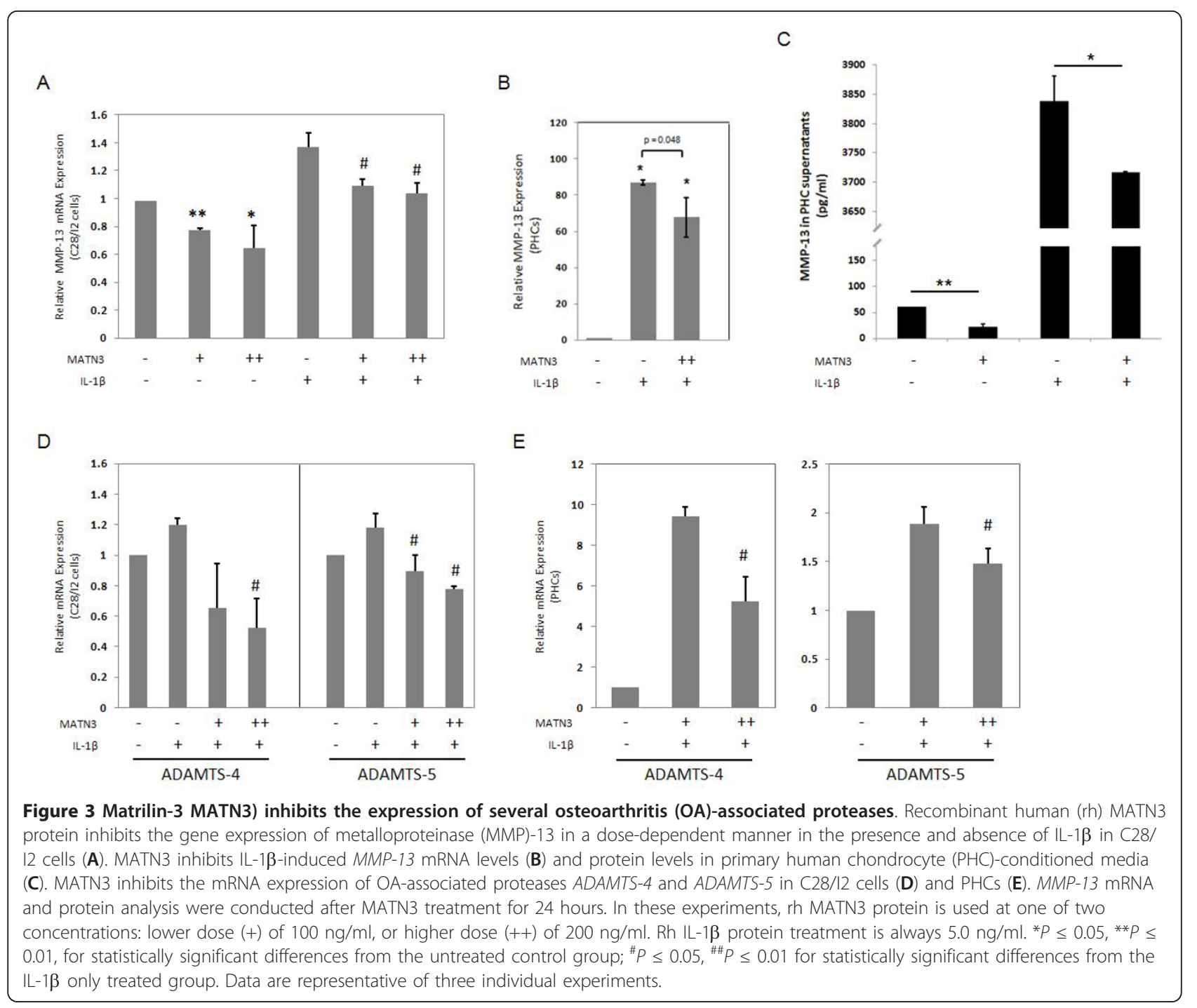

partly dependent on IL-1Ra. In contrast, knocking down $I L-1 R a$ did not increase the basal level of $M M P-13$ gene expression (Figure 6B). In addition, MATN3 inhibition of $M M P-13$ gene expression was significant in both control and $I L-1 R a$ knock-down cells suggesting that MATN3 inhibition of $M M P-13$ is not mediated by IL-1Ra.

\section{Discussion}

Mutations in human MATN3 are associated with a variety of human cartilage degenerative diseases including chondrodysplasia and OA [6-9]. These genetic studies strongly suggest that the normal MATN3 gene product is chondroprotective. Since MATN3 protein is an ECM protein, an accepted hypothesis is that its chondroprotective activity is due to its structural properties, which may help to maintain tissue integrity [47]. In this study however, we hypothesized that MATN3 may also be capable of preventing the IL- $1 \beta$-induced disregulation of cartilage homeostasis genes thereby preventing the hallmark of OA development.

Here we demonstrated that rhMATN3 protein induces gene expression of $I L-1 R a$ in three chondrocyte culture models: immortalized human C28/I2 chondrocytes, PHCs and PMCs. MATN3 increased $I L-1 R a$ mRNA production in the presence and absence of the inflammatory cytokine IL- $1 \beta$ in a dose- and time-dependent manner. Furthermore, MATN3 treatment increased the soluble IL-1Ra protein levels in the presence of IL-1 $\beta$ in chondrocytes, as determined by ELISA and Bio-Plex Array analysis.

IL-1Ra, an IL- $1 \alpha / \beta$ protein mimic, is a major endogenous inhibitor of the IL-1 $\beta$ pathway $[12,41-43]$. It binds IL-1R1, thereby preventing IL-1 downstream signaling. IL$1 \mathrm{Ra}$ is potentially chondroprotective, since it inhibits IL$1 \beta$, which is a major stress and inflammation cytokine that is closely associated with OA pathogenesis. The concentration of soluble IL-1Ra decreases with increasing grades 
A

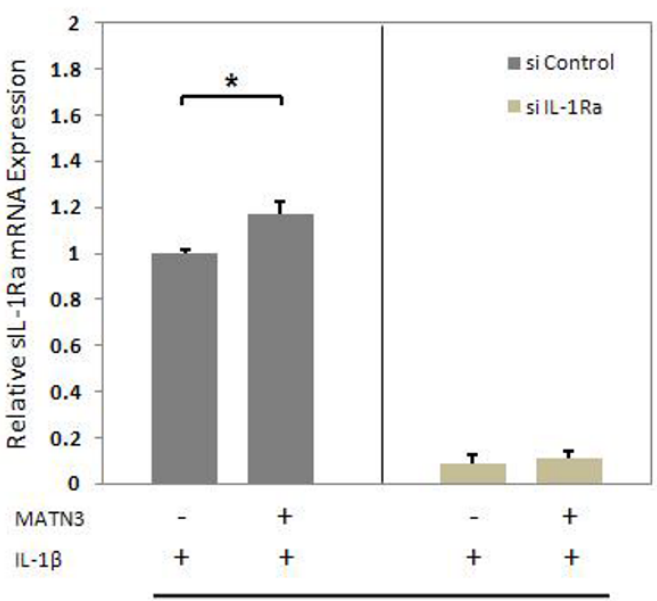

24 hrs.

C

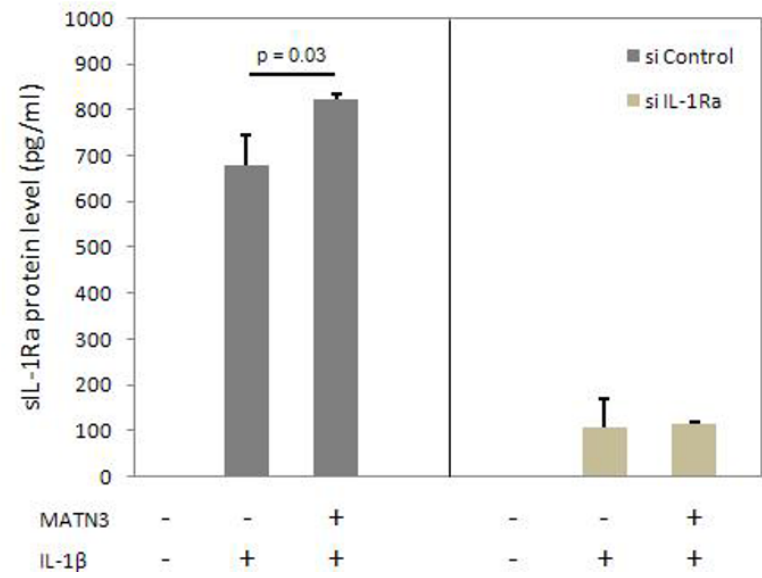

B

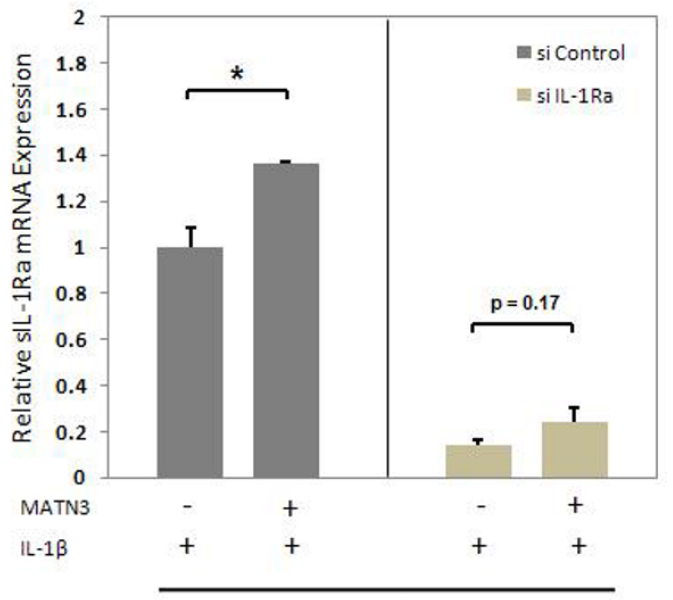

36 hrs.

Figure 4 Small interfering RNA significantly suppresses mRNA and protein levels of IL-1Ra. Knocking down all isoforms of IL-1Ra via IL1RN siRNA treatment reduces the IL-1 $\beta$ induction of this gene as observed at two time points $(24,36$ hours) post cell culture treatment (A, B). This also results in significant reduction of soluble IL-1Ra protein levels in primary human chondrocyte (PHC) cell supernatants after 24 hours (C). PHCs treated with a nonspecific scrambled siRNA construct is used as the control group. For these experiments, recombinant human (rh) matrilin-3 (MATN3) protein is used at $200 \mathrm{ng} / \mathrm{ml}$. Rh IL-1 $\beta$ protein treatment is always $5.0 \mathrm{ng} / \mathrm{ml} .{ }^{*} P \leq 0.05$ for statistically significant differences between groups. Data are representative of three individual experiments.

of articular chondral damage in human patients [48]. Knocking down $I L-1 R a$ results in the early onset of arthritis in multiple mouse genetic backgrounds. $I L-1 R a \mathrm{KO}$ mice bred in both BALB/cA and MFIx129 backgrounds developed severe inflammatory arthritis [49]. Conversely, in vivo IL-1Ra gene transfer reduces surgically induced OA severity in rabbits [50]. The level of IL-1Ra present in the rabbit synovium positively correlated with the reduction in articular cartilage lesions.

Because of its chondroprotective properties, it is of paramount importance to study how $I L-1 R a$ gene expression is regulated. IL-1Ra is produced by many cell types including chondrocytes [51]. It is important to recognize that the chondroprotective effects of IL-1Ra in OA are only observable when the protein is consistently present in the arthritic joint. This explains why short-lived drugs based on IL-1Ra (that is, AnikinRA) [52], which only last a few hours post-intra-articular injection into human patients, have limited efficacy in OA treatment [53]. Thus, finding a means of continuously stimulating autologous IL-1Ra production in chondrocytes may provide an effective alternative for sustaining articular cartilage integrity by dampening inflammation under arthritic conditions. We show here 
A

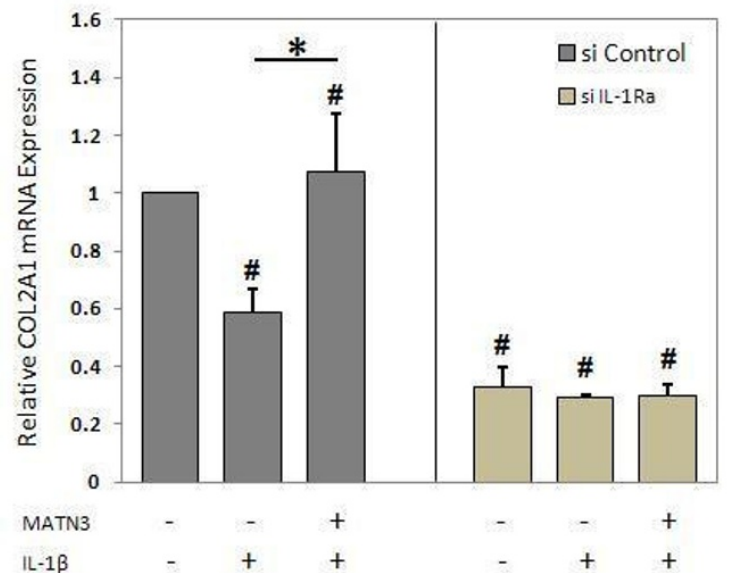

B
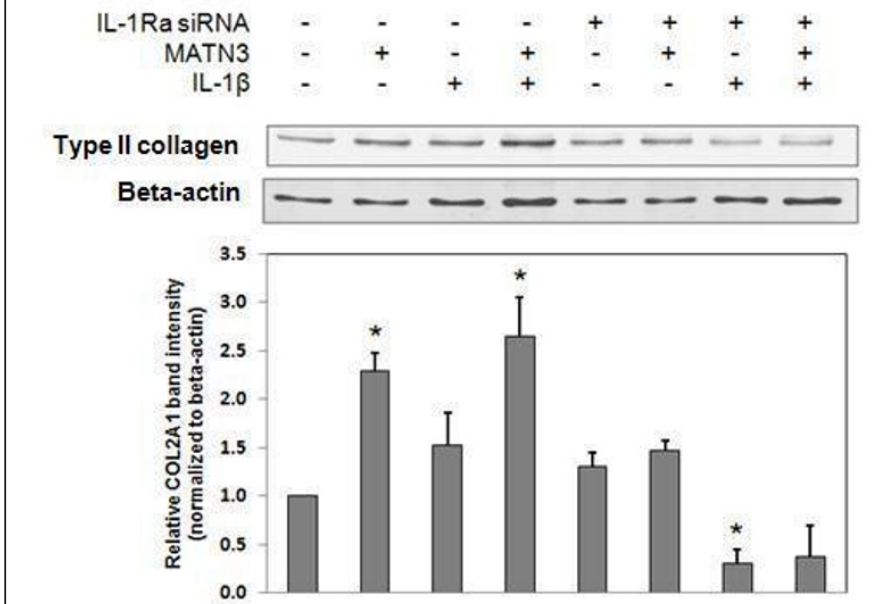

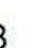

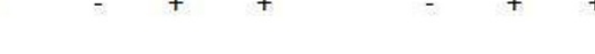

C

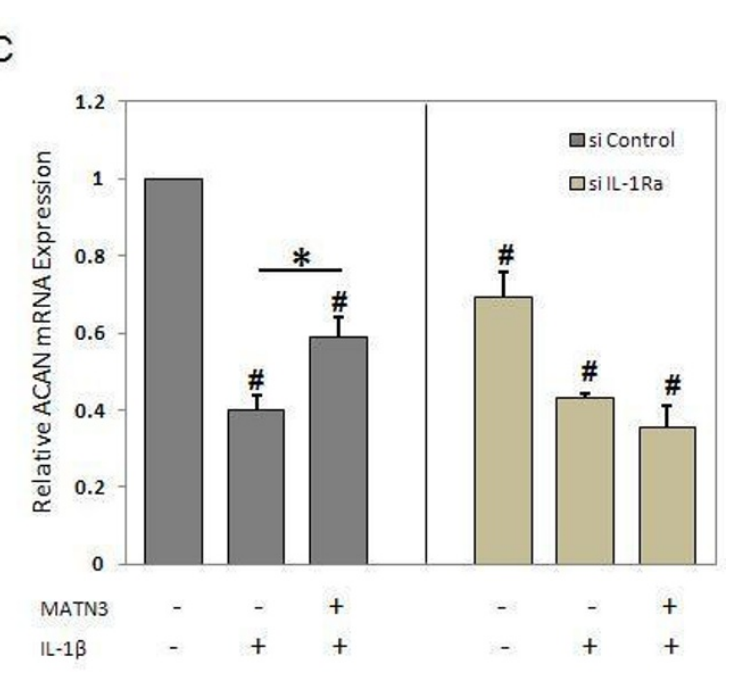




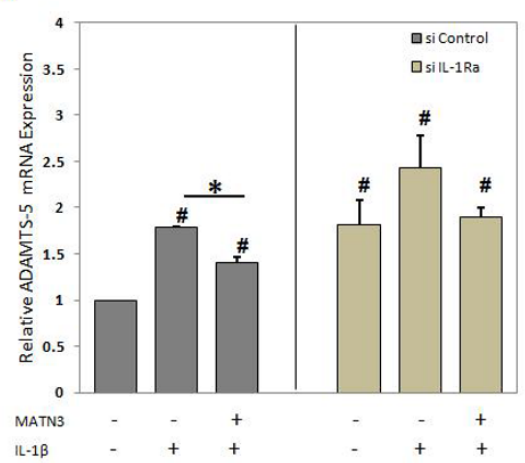

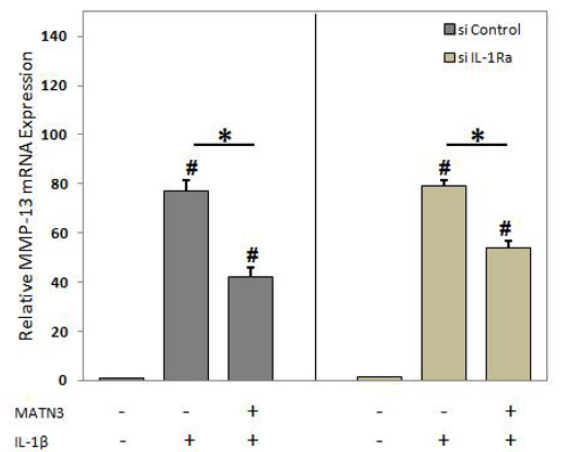

Figure 6 Matrilin-3 MATN3) inhibition of ADAMTS-5 gene expression require IL-1Ra. Knocking down IL-1Ra in primary human chondrocytes (PHCS) only partially affects MATN3-induced inhibition of ADAMTS-5 (A) and does not seem to significantly affect MMP-13 gene expression (B). The concentration of recombinant human MATN3 protein used was $200 \mathrm{ng} / \mathrm{ml}$ and of IL-1 $\beta$ was $5.0 \mathrm{ng} / \mathrm{ml}$. Gene expression analysis was conducted 36 hours post exposure to cell culture treatment conditions. ${ }^{~} P \leq 0.05$ for statistically significant differences from the untreated group; ${ }^{*} P \leq 0.05$ for statistically significant differences between groups. Individual experiments were done in biological triplicate per patient sample. Data are representative of five individual experiments.

$A C A N$. Conversely, the lack of MATN3 resulted in reduced basal expression of these chondrogenic genes in MATN3 KO mice in comparison to wild-type mice of the same genetic background. The levels of both Col2a1 and Acan were reduced by approximately $50 \%$ compared to wild-type mice. Thus, MATN3 is necessary to maintain normal expression of these genes in cartilage. It is interesting that MATN3 $\mathrm{KO}$ mice have relatively normal skeletal development [10] despite reduced levels of Col2a1 and Acan as observed here for the first time. This is consistent with the finding that Col2aland Acanheterozygous $\mathrm{KO}$ mice have normal skeletal development at birth $[54,55]$. However, our data also show that, while IL-1 $\beta$ treatment greatly reduces the levels of COL $2 A 1$ and $A C A N$ in chondrocytes, the presence of MATN3 inhibits this further reduction of matrix synthesis by IL-1 $\beta$. Since the IL-1 $\beta$ levels are often elevated in OA, the lack of MATN3 may result in a more severe phenotype during skeletal aging than during development. Thus, this newly discovered MATN3 property of inhibiting IL-1 $\beta$ may explain why the lack of MATN3 results in accelerated OA during aging despite relatively normal skeletal development in MATN3 KO mice [10].

MATN3 protein not only maintained expression of anabolic genes including COL2A1 and $A C A N$ in our experiments, but also inhibited expression of catabolic genes induced by IL- $1 \beta$, including $M M P-13, A D A M T S-4$ and -5 . This inhibitory effect correlated with the concentration of MATN3 protein in the culture medium. These catabolic genes are closely related to OA pathogenesis with increased gene expression and/or activity [12]. The lack of the ADAMTS-5 gene also protects cartilage degeneration from abnormal mechanical loading in the mouse joint [20]. Thus, inhibiting gene expression of these OA-associated matrix proteases induced by IL- $1 \beta$ may also contribute to the chondroprotective properties of MATN3.

Since MATN3 induces $I L-1 R a$ expression and inhibits the effects of IL-1 $\beta$ in chondrocytes, we determined whether these two events are dependent. Knocking down $I L-1 R a$ using siRNA abolished both $I L-1 R a$ mRNA and protein levels in chondrocytes. This was also confirmed by the failure of IL-1 $\beta$ treatment to induce $I L-1 R a$ expression in the $I L-1 R a$ knocked-down chondrocytes. The levels of COL2A1 and ACAN mRNA levels were significantly lower in these $I L-1 R a$ knocked-down chondrocytes compared to wild-type chondrocytes. Furthermore, treatment with MATN3 protein failed to significantly enhance COL2A1 and $A C A N$ mRNA levels in the presence of IL-1 $\beta$. Similarly, western blot analysis indicated that silencing $I L-1 R a$ resulted in an overall reduction of COL2A1 protein level. Silencing $I L-1 R a$ also completely abolished MATN3 induction of COL2A1 protein level, both in the absence and presence of IL-1 $\beta$. This suggests that the ability of MATN3 to maintain anabolic markers such as COL2A1 and $A C A N$ in chondrocytes depends on the presence of IL-1Ra.

Our study reveals that MATN3 inhibition of IL- $1 \beta$-stimulated expression of catabolic proteases is mediated by both IL-1Ra-dependent and -independent pathways. In the $I L-1 R a$ knocked-down cells, ADAMTS-5 mRNA levels were significantly increased in comparison to wildtype chondrocytes, while $M M P-13$ mRNA levels remained unchanged. Upon IL-1 $\beta$ treatment, MATN3 inhibition of the stimulation of ADAMTS-5 in IL-1Ra knocked-down chondrocytes became statistically insignificant. In contrast, MATN3 still significantly inhibited the stimulation of $M M P-13$ by IL-1 $\beta$ in the knocked-down 
cells as in wild-type chondrocytes. The same was true for ADAMTS-4 gene expression as well (not shown). This indicates that MATN3 inhibition of IL-1 $\beta$ upregulation of $A D A M T S-5$ is IL-1Ra-dependent, while its inhibition of IL-1 $\beta$ upregulation of $M M P-13$ and $A D A M T S-4$ is not. In addition to IL-1Ra, there are other antagonists in the IL-1 $\beta$ signaling pathway including a decoy receptor IL-1RII, an inhibitory receptor SIGIRR, and a soluble receptor sIL-1RAcP $[56,57]$. MATN3 may inhibit IL-1 $\beta$ stimulation of MMP-13 by upregulating one of these antagonists. Alternatively, MATN3 may also exert its regulatory function by downregulating agonists in the IL-1 signaling pathway that are independent of IL-1Ra. A limitation of this study involves the use of a relatively small patient pool (total of three to five patients) for the acquisition of primary human chondrocytes. The conclusion of MATN3 induction of IL-1Ra is, however, valid in chondrocytes from each patient. Thus, experiments involving the use of primary human chondrocyte cultures accomplished its intended purpose of corroborating the findings observed in the C28/I2 human chondrocyte cell line.

The mechanism by which MATN3 regulates IL-1Ra is currently unknown. Given that $I L-1 R a$ mRNA transcript levels are elevated relatively quickly (within 24 hours of exposure to MATN3 recombinant protein), the stimulation by MATN3 of this anti-inflammatory cytokine may be a direct effect. Cartilage extracellular matrix molecules such as hyaluronan have previously been shown to mediate regulatory functions by direct interaction with cell surface molecules and/or receptors [58,59]. It is possible that chondrocytes have an endogenous receptor through which MATN3 signals to mediate its regulatory function (s). It has been shown previously that matrilins may interact with integrins or other plasma membrane receptors in chondrocytes [60]. It remains to be determined whether the regulatory functions of MATN3, as shown here, are mediated by these receptors.

We have shown that MATN3 treatment inhibits OAassociated catabolic gene expression. Interestingly, a previous study has shown that treatment of human chondrocytes with very high concentrations of murine recombinant MATN3 protein leads to activation of OAassociated catabolic genes [61]. It is important to note that there are two clear differences between the aforementioned study and this one. The first is that, while mouse recombinant MATN3 was used to treat PHCs in the previous study, we used human recombinant MATN3 to treat human cells in this study. The second, and perhaps a major difference, is the concentration of recombinant MATN3 used to treat chondrocytes. Recombinant MATN3 protein was used at 5 to $50 \mu \mathrm{g} / \mathrm{ml}$ concentrations in the previous study, which is 50 to 500 times higher than the concentrations (100 to $200 \mathrm{ng} / \mathrm{ml}$ ) used in this study. Proteins at concentrations significantly higher than the physiological levels may exert toxic effects on cells thereby triggering production of degenerative proteases. Indeed, chondrocytes treated with type II collagen at the same high concentrations also induced matrix protease expression in the previous study [61]. Thus, the data from the two studies indicate that MATN3 is chondroprotective at the 100 to $200 \mathrm{ng} / \mathrm{ml}$ concentration range, while stimulating catabolic pathways at the 5 to $50 \mu \mathrm{g} / \mathrm{ml}$ concentration range, which may reflect supra-physiological levels.

\section{Conclusion}

This study presents evidence of several novel regulatory functions of MATN3, including induction of IL-1Ra expression, maintenance of collagen II and aggrecan gene expression, and inhibition of the IL- $1 \beta$-induced gene expression of certain catabolic matrix proteases including ADAMTS-5. These regulatory functions are MATN3 concentration-dependent. We further demonstrate that some of these regulatory functions (that is, enhancement of COL2A1 and ACAN gene expression) are dependent on IL-1Ra, while other regulatory functions are independent (that is, inhibition of IL-1 $\beta$-induced MMP-13 gene expression). These observations were made in multiple chondrocyte culture models, including primary and immortalized cells, and human and mouse species. It provides a novel mechanism for chondroprotective properties of MATN3, which has been strongly indicated by previous genetic studies in humans and mice. It suggests that MATN3 plays not only a structural role in cartilage ECM, but also a regulatory role in cartilage homeostasis by modulating genes critical for matrix synthesis, degradation, and inflammation. It also raises an intriguing possibility of using MATN3, a cartilage matrix protein, for stimulating endogenous anti-inflammatory and chondroprotective properties in cartilage.

\section{Additional material}

\footnotetext{
Additional file 1: Kinetics of matrilin-3 (MATN3)-induced IL-1Ra gene expression in human chondrocytes. A figure showing MATN3 stimulation of $/ L-1 R$ a gene upregulation by $C 28 / 12$ cells and primary human chondrocytes (PHCs) in the absence $(\mathbf{A}, \mathbf{C})$ and presence of IL-1 $\beta$ (B, D). Cells were treated with 0,100 or $200 \mathrm{ng} / \mathrm{ml}$ of recombinant human MATN3 protein. IL-1 $\beta$ was used at a concentration of $5.0 \mathrm{ng} / \mathrm{ml}$. ${ }^{*} P \leq 0.05$ for statistically significant differences relative to the $0 \mathrm{ng} / \mathrm{ml}$ treatment group, for each respective time point. Individual experiments were done in biological triplicate.

Additional file 2: Matrilin-3 (MATN3) stimulates type II collagen (COL2A1) mRNA levels for at least 24 hours in human chondrocytes A figure showing that MATN3 induces COL2A1 mRNA levels in C28/12 cells $(\mathbf{A})$ and primary human chondrocytes (PHCs) (B) after 24 hours treatment. Recombinant human (rh) MATN3 protein is used at $200 \mathrm{ng} / \mathrm{ml}$ and $\mathrm{rh} \mathrm{IL}-1 \beta$ protein treatment is used at $5.0 \mathrm{ng} / \mathrm{ml}$. ${ }^{*} P \leq 0.05$ for statistically significant differences from the untreated control group;
} 
${ }^{\#} P \leq 0.05$ for statistically significant differences from the $\mathrm{IL}-1 \beta$ only treated group. Data are representative of three individual experiments.

\section{Abbreviations}

ACAN: aggrecan; ANOVA: one-way analysis of variance; COL2A1: type ॥ collagen, DMEM: Dubecco's modified Eagle's medium; ECM: extracellular matrix, EGF: epidermal growth factor; ELISA: enzyme-linked immunosorbent assay; FBS: fetal bovine serum; HBSS: Hank's Balanced Salt Solution; IL-1ß: interleukin-1 beta; IL-1Ra: interleukin-1 receptor antagonist; KO: knockout; MATN3: matrilin-3; MED: multiple epiphyseal dysplasia; MMP: matrix metalloproteinase; NO: nitric oxide; OA: osteoarthritis; PBS: phosphatebuffered saline; PHC: primary human chondrocyte; PMC: primary mouse chondrocyte; RT-qPCR: real time quantitative polymerase chain reaction; rh: recombinant human; SEMD: spondylo-epi-metaphyseal dysplasia; sIL-1Ra: soluble interleukin-1 receptor antagonist; siRNA: small interfering ribonucleic acid; vWFA: Von Willebrand Factor $A$

\section{Acknowledgements}

This study is supported by NIH grants AG 014399, AG 017021, and RR024484. Dr. Goldring's research is supported by R01-AG022021.

\section{Author details}

${ }^{1}$ Department of Orthopedics; Warren Alpert Medical School of Brown University, Providence RI 02903, USA. ${ }^{2}$ Research Division, The Hospital for Special Surgery, and Department of Cell and Developmental Biology, Weill Cornell Medical College, New York, NY 10021, USA.

\section{Authors' contributions}

In addition to conducting all cell culture experiments and mRNA/protein analyses, CTJ played a significant role in study design, interpretation and composition of this manuscript. MBG provided the C28/I2 human chondrocyte cell line, which was crucial for this study. She also contributed greatly to data discussion and interpretation. RT is the orthopedic surgeon who extracted the patient cartilage samples that were used for isolating the primary human chondrocytes in this study. He also contributed greatly to data discussion and interpretation. QC (corresponding author) designed all experiments and played a pivotal role in data discussion/interpretation and manuscript composition. This manuscript was read and approved by all aforementioned authors.

\section{Authors' information}

$\mathrm{CT}$ Jayasuriya, Ph.D candidate of Pathobiology Graduate Program (Brown University); MB Goldring, Ph.D, Professor of Cell and Developmental Biology (Weill Cornell Medical College); R Terek, MD, MA, Associate Professor of Orthopaedics (Warren Alpert Medical School of Brown University); Q Chen, Ph.D, Professor of Medical Science (Brown University).

\section{Competing interests}

The authors declare that they have no competing interests.

Received: 30 March 2012 Revised: 28 July 2012

Accepted: 21 August 2012 Published: 11 September 2012

\section{References}

1. Deák F, Wagener R, Kiss I, Paulsson M: The matrilins: a novel family of oligomeric extracellular matrix proteins. Matrix Biol 1999, 18:55-64

2. Wagener R, Kobbe B, Paulsson M: Primary structure of matrilin-3, a new member of a family of extracellular matrix proteins related to cartilage matrix protein (matrilin-1) and von Willebrand factor. FEBS Lett 1997, 413:129-134

3. Piecha D, Muratoglu S, Morgelin M, Hauser N, Studer D, Kiss I, Paulsson M, Deák F: Matrilin-2, a large, oligomeric matrix protein, is expressed by a great variety of cells and forms fibrillar networks. J Biol Chem 1999, 274:13353-13361.

4. Klatt A, Nitsche DP, Kobbe B, Macht M, Paulsson M, Wagener R: Molecular structure, processing, and tissue distribution of matrilin-4. J Biol Chem 2001, 276:17267-17275
5. Klatt A, Nitsche DP, Kobbe B, Morgelin M, Paulsson M, Wagener R: Molecular structure and tissue distribution of matrilin-3, a filamentforming extracellular matrix protein expressed during skeletal development. J Biol Chem 2000, 275:3999-4006.

6. Mostert AK, Dijkstra PF, Jansen BR, van Horn JR, de Graaf B, Heutink P, Lindhout D: Familial multiple epiphyseal dysplasia due to a matrilin-3 mutation: further delineation of the phenotype including 40 years follow-up. Am J Med Genet A 2003, 120A:490-497.

7. Cotterill SL, Jackson GC, Leighton MP, Wagener R, Mäkitie O, Cole WG, Briggs : Multiple epiphyseal dysplasia mutations in MATN3 cause misfolding of the A-domain and prevent secretion of mutant matrilin-3. Hum Mutat 2005, 26:557-565.

8. Stefansson SE, Jonsson $\mathrm{H}$, Ingvarsson T, Manolescu I, Jonsson $\mathrm{H}$, Olafsdottir G, Pálsdóttir E, Stefánsdóttir G, Sveinbjörnsdóttir G, Frigge ML, Kong A, Gulcher JR, Stefánsson K: Genomewide scan for hand osteoarthritis: a novel mutation in matrilin-3. Am J Hum Genet 2003, 72:1448-1459.

9. Borochowitz ZU, Scheffer D, Adir V, Dagoneau N, Munnich A, CormierDaire V: Spondylo-epi-metaphyseal dysplasia (SEMD) matrilin 3 type: homozygote matrilin 3 mutation in a novel form of SEMD. J Med Genet 2004, 41:366-372.

10. Weyden L, Wei L, Luo J, Yang X, Birk D, Adams D, Bradley A, Chen Q: Functional knockout of the matrilin-3 gene causes premature chondrocyte maturation to hypertrophy and increases bone mineral density and osteoarthritis. Am J Pathol 2006, 169:515-527.

11. Pullig O, Weseloh G, Klatt AR, Wagener R, Swoboda B: Matrilin-3 in human articular cartilage: increased expression in osteoarthritis. Osteoarthritis Cartilage 2002, 10:253-263.

12. Martel-Pelletier J, Boileau C, Pelletier JP, Roughley PJ: Cartilage in normal and osteoarthritis conditions. Best Pract Res Clin Rheumatol 2008, 22:351-384.

13. Takaishi H, Kimura T, Dalal S, Okada Y, D'Armiento J: Joint diseases and matrix metalloproteinases: a role for MMP-13. Curr Pharm Biotechnol 2008, 9:47-54.

14. Ohta S, Imai K, Yamashita K, Matsumoto T, Axumano I, Okada Y: Expression of matrix metalloproteinase 7 (matrilysin) in human osteoarthritic cartilage. Lab Invest 1998, 78:79-87.

15. Mitchell PG, Magna HA, Reeves LM, Lopresti-Morrow LL, Yocum SA Rosner PJ, Geoghegan KF, Hambor JE: Cloning, expression, and type II collagenolytic activity of matrix metalloproteinase-13 from human osteoarthritic cartilage. J Clin Invest 1996, 97:761-768.

16. Drummond AH, Beckett $P$, Brown PD, Bone EA, Davidson AH, Galloway WA, Gearing AJ, Huxley P, Laber D, McCourt M, Whittaker M, Wood LM, Wright A: Preclinical and clinical studies of MMP inhibitors in cancer. Ann NY Acad Sci 1999, 878:228-235.

17. Imai K, Ohta S, Matsumoto T, Fujimoto N, Sato H, Seiki M, Okada Y: Expression of membrane-type 1 matrix metalloproteinase and activation of progelatinase A in human osteoarthritic cartilage. Am J Pathol 1997, 151:245-256.

18. Mohtai M, Smith RL, Schurman DJ, Tsuji Y, Torti FM, Hutchinson NI, StetlerStevenson WG, Goldberg Gl: Expression of 92-kD type IV collagenase/ gelatinase (gelatinase B) in osteoarthritic cartilage and its induction in normal human articular cartilage by interleukin 1. J Clin Invest 1993, 92:179-185.

19. Okada Y, Shinmei M, Tanaka O, Naka K, Kimura A, Nakanishi I, Bayliss MT, Iwata K, Nagase H: Localization of matrix metalloproteinase 3 (stromelysin) in osteoarthritic cartilage and synovium. Lab Invest 1992, 66:680-690.

20. Glasson S, Askew R, Sheppard B: Depletion of active ADAMTS5 prevents cartilage degradation in murine model of osteoarthritis. Nature 2005, 434:644-648.

21. Stanton $H$, Rogerson FM, East CJ: ADAMTS5 is the major aggrecanase in mouse cartilage in vivo and in vitro. Nature 2005, 434:648-652.

22. Aida Y, Maeno M, Suzuki N, Shiratsuchi H, Motohashi M, Matsumura H: The effect of IL-1beta on the expression of matrix metalloproteinases and tissue inhibitors of matrix metalloproteinases in human chondrocytes. Life Sci 2005, 77:3210-3221.

23. Goldring MB, Birkhead J, Suen L, Yamin R, Mizuno S, Glowacki J, Arbiser JL, Apperley JF: Interleukin-1 beta-modulated gene expression in immortalized human chondrocytes. J Clin Invest 1994, 94:2307-2316. 
24. Attur MG, Patel IR, Patel RN, Abramson SB, Amin AR: Autocrine production of IL-1 beta by human osteoarthritis-affected cartilage and differential regulation of endogenous nitric oxide, IL-6, prostaglandin E2, and IL-8. Proc Assoc Am Physicians 1998, 110:65-72.

25. Daheshia M, Yao JQ: The interleukin 1beta pathway in the pathogenesis of osteoarthritis. J Rheumatol 2008, 35:2306-2312.

26. Ahmad R, Qureshi HY, Mabrouk M, Sylvester J, Ahmad M, Zafarullah M: Inhibition of interleukin 1-induced matrix metalloproteinase 13 expression in human chondrocytes by interferon gamma. Ann Rheum Dis 2006, 66:782-789.

27. Wilson HM, Haites NE, Reid FJ, Booth NA: Interleukin-1 beta up-regulates the plasminogen activator/plasmin system in human mesangial cells. Kidney Int 1996, 49:1097-1104.

28. Bau B, Gebhard PM, Haag J: Relative messenger RNA expression profiling of collagenases and aggrecanases in human articular chondrocytes in vivo and in vitro. Arthritis Rheum 2002, 46:2648-57.

29. Gabay O, Sanchez C, Salvat C, Chevy F, Breton M, Nourissat G, Wolf C, Jacques C, Berenbaum F: Stigmasterol: a phytosterol with potential antiosteoarthritic properties. Osteoarthritis Cartilage 2010, 18:106-116.

30. Song RH, Tortorella MD, Malfait AM, Alston JT, Yang Z, Arner EC, Griggs DW Aggrecan degradation in human articular cartilage explants is mediated by both ADAMTS-4 and ADAMTS-5. Arthritis Rheum 2007, 56:575-585.

31. Martin J, Steadman R, Knowlden J, Williams J, Davies M: Differential regulation of matrix metalloproteinases and their inhibitors in human glomerular epithelial cells in vitro. J Am Soc Nephrol 1998, 9:1629-1637.

32. Chandrasekhar S, Harvey AK, Johnson MG, Becker GW: Osteonectin/SPARC is a product of articular chondrocytes/cartilage and is regulated by cytokines and growth factors. Biochim Biophys Acta 1994, 1221:7-14.

33. Fukuo K, Birkhead JR, Dudek E, Sandell L: Transcriptional suppression by interleukin-1 and interferon-gamma of type II collagen gene expression in human chondrocytes. J Cell Biochem 1994, 54:85-99.

34. Gibson GJ, Beaumont BW, Flint MH: Synthesis of a low molecular weight collagen by chondrocytes from the presumptive calcification region of the embryonic chick sterna: the influence of culture with collagen gels. J Cell Biol 1984, 99:208-216.

35. Grammatopoulos DK, Hillhouse EW: Basal and interleukin-1betastimulated prostaglandin production from cultured human myometrial cells: differential regulation by corticotropin-releasing hormone. J Clin Endocrinol Metab 1999, 84:2204-2211.

36. Huang HY, Wen Y, Kruessel JS, Raga F, Soong YK, Polan ML: Interleukin (IL)$1 \beta$ Regulation of IL-1 $\beta$ and IL-1 Receptor Antagonist Expression in Cultured Human Endometrial Stromal Cells. J Clin Endocrinol Metab 2001, 86:1387-1393.

37. Tetlow LC, Adlam DJ, Woolley DE: Matrix metalloproteinase and proinflammatory cytokine production by chondrocytes of human osteoarthritic cartilage. Arthritis Rheum 2001, 44:585-594.

38. Attur MG, Dave M, Cipolletta C, Kang P, Goldring MB, Patel IR, Abramson SB, Amin AR: Reversal of autocrine and paracrine effects of interleukin 1 (IL-1) in human arthritis by type II IL-1 decoy receptor. Potential for pharmacological intervention. J Biol Chem 2000, 275:40307-40315.

39. Barakat AF, Elson CJ, Westacott CI: Susceptibility to physiological concentrations of IL-1 beta varies in cartilage at different anatomical locations on human osteoarthritic knee joints. Osteoarthritis Cartilage 2002, 10:264-269.

40. Imagawa $\mathrm{K}$, de Andres MC, Hashimoto K, Pitt D, Itoi E, Goldring MB, Roach HI, Oreffo RO: The epigenetic effect of glucosamine and a nuclear factor-kappa B (NF-kB) inhibitor on primary human chondrocytesimplications for osteoarthritis. Biochem Biophys Res Commun 2011, 405:362-367.

41. Arend WP, Gabay C: Physiologic role of interleukin-1 receptor antagonist. Arthritis Res 2000, 2:245-248.

42. Gabay C, Lamacchia C, Palmer G: IL-1 pathways in inflammation and human diseases. Nat Rev Rheumatol 2010, 6:232-241.

43. Dayer JM: The process of identifying and understanding cytokines: from basic studies to treating rheumatic diseases. Best Pract Res Clin Rheumatol 2004, 18:31-45

44. Otero M, Plumb DA, Tsuchimochi K, Dragomir CL, Hashimoto K, Peng H, Olivotto E, Bevilacqua M, Tan L, Yang Z, Zhan Y, Oettgen P, Li Y, Marcu KB, Goldring MB: E74-like factor 3 (ELF3) impacts on matrix metalloproteinase 13 (MMP13) transcriptional control in articular chondrocytes under proinflammatory stress. J Biol Chem 2012, 287:3559-3572

45. Mayne R, Mayne PM, Ren Z, Accavitti MA, Gurusiddappa S, Scott PG Monoclonal antibody to the aminotelopeptide of type II collagen: loss of the epitope after stromelysin digestion. Connect Tissue Res 1994, 31:11-21.

46. Pei M, Luo J, Chen Q: Enhancing and maintaining chondrogenesis of synovial fibroblasts by cartilage extracellular matrix protein matrilins. Osteoarthritis Cartilage 2008, 16:1110-1117.

47. Budde B, Blumbach K, Ylöstalo J, Zaucke F, Ehlen HW, Wagener R, AlaKokko L, Paulsson M, Bruckner P, Grässel S: Altered integration of matrilin3 into cartilage extracellular matrix in the absence of collagen IX. Mol Cell Biol 2005, 25:10465-10478.

48. Marks PH, Donaldson ML: Inflammatory cytokine profiles associated with chondral damage in the anterior cruciate ligament-deficient knee. Arthroscopy 2005, 21:1342-1347

49. Nicklin MJ, Hughes DE, Barton JL, Ure JM, Duff GW: Arterial inflammation in mice lacking the interleukin 1 receptor antagonist gene. J Exp Med 2000, 191:303-312

50. Fernandes J, Tardif G, Martel-Pelletier J, Lascau-Coman V, Dupuis M, Moldovan F, Sheppard M, Krishnan BR, Pelletier JP: In vivo transfer of interleukin-1 receptor antagonist gene in osteoarthritic rabbit knee joints: prevention of osteoarthritis progression. Am J Pathol 1999, 154:1159-1169.

51. Baragi VM, Renkiewicz RR, Jordan H, Bonadio J, Hartman JW, Roessler BJ: Transplantation of transduced chondrocytes protects articular cartilage from interleukin 1-induced extracellular matrix degradation. J Clin Invest 1995, 96:2454-2460.

52. Stanley B, Cohen MD: The use of anakinra, an interleukin-1 receptor antagonist, in the treatment of rheumatoid arthritis. Rheum Dis Clin N Am 2004, 30:365-380.

53. Chevalier X, Goupille P, Beaulieu AD, Burch FX, Bensen WG, Conrozier T, Loeuille D, Kivitz AJ, Silver D, Appleton BE: Intraarticular injection of anakinra in osteoarthritis of the knee: A multicenter, randomized, double-blind, placebo-controlled study. Arthritis Rheum 2009, 61:344-352.

54. Li SW, Prockop DJ, Helminen H, Fässler R, Lapveteläinen T, Kiraly K, Peltarri A, Arokoski J, Lui H, Arita M, Khillan JS: Transgenic mice with targeted inactivation of the Col2 alpha 1 gene for collagen II develop a skeleton with membranous and periosteal bone but no endochondral bone. Genes Dev 1995, 9:2821-2830

55. Watanabe H, Yamada Y: Chondrodysplasia of gene knockout mice for aggrecan and link protein. Glycoconj J 2002, 19:269-273.

56. Dinarello CA: Interleukin-1. Cytokine Growth Factor Rev 1997, 8(4):253-265.

57. Wald D, Qin J, Zhao Z, Qian Y, Naramura M, Tian L, Towne J, Sims JE, Stark GR, Li X: SIGIRR, a negative regulator of Toll-like receptorinterleukin 1 receptor signaling. Nat Immunol 2003, 4:920-927.

58. Aguiar DJ, Knudson W, Knudson CB: Internalization of the hyaluronan receptor CD44 by chondrocytes. Exp Cell Res 1999, 252:292-302.

59. Yatabe T, Mochizuki S, Takizawa M, Chijiiwa M, Okada A, Kimura T, Fujita Y, Matsumoto $\mathrm{H}$, Toyama $Y$, Okada Y: Hyaluronan inhibits expression of ADAMTS4 (aggrecanase-1) in human osteoarthritic chondrocytes. Ann Rheum Dis 2009, 68:1051-1058.

60. Mann HH, Sengle G, Gebauer JM, Eble JA, Paulsson M, Wagener R: Matrilins mediate weak cell attachment without promoting focal adhesion formation. Matrix Biol 2007, 26:167-174.

61. Klatt AR, Klinger G, Paul-Klausch B, Kühn G, Renno JH, Wagener R, Paulsson M, Schmidt J, Malchau G, Wielckens K: Matrilin-3 activates the expression of osteoarthritis-associated genes in primary human chondrocytes. FEBS Lett 2009, 583:3611-3617.

doi:10.1186/ar4033

Cite this article as: Jayasuriya et al:: Matrilin-3 Induction of IL-1 receptor antagonist Is required for up-regulating collagen II and aggrecan and down-regulating ADAMTS-5 gene expression. Arthritis Research \& Therapy 2012 14:R197. 